\title{
UNA FUENTE DESCONOCIDA PARA LA DESCRIPCIÓN DE LA GALERA REAL (CON UNOS PARALELOS TEXTUALES EN LA OBRA DE CRISTÓBAL MOSQUERA DE FIGUEROA YJUAN DE MAL LARA)
}

Entre las variadas directrices que permitieron las formalizaciones del canon en la poesía sevillana de la segunda mitad del siglo XVI, la proyección épico-mitográfica propuesta por el humanista Juan de Mal Lara (1526-1571) ${ }^{1}$ se erige como emblema cardinal. Tal vigencia genológica, que dejó su huella en Fernando de Herrera, Juan de la Cueva y Cristóbal Mosquera de Figueroa, arroja luz, al tiempo, sobre el preludio de una épica manierista en Las lágrimas de Angélica de Luis Barahona de Soto ${ }^{2}$. Esta obra, en efecto, brinda moralidades a modo de paratextos -como en los poemas mitográficos de Mal Lara-y una alusión, a la par, al personaje apuleyano de Psique, rememorando el testimonio homónimo del maestro hispalense. En lo que concierne a Fernando de Herrera (1534-1597), rasgos esenciales de su poesía -elección y manejo de referentes míticos, la consideración del vuelo heroico-patriótico y religioso, etc.- se justifican, contextualmente, en la lectura atenta de las composiciones de Mal Lara, sobre todo, el Hércules $^{3}$. Y si ambos coincidían en formular la canonización de Garcilaso de la Vega mediante diversas estrategias discursivas, del mismo modo, reivindicaron para sí un lugar de privilegio, bien junto a

${ }^{1}$ Editamos sus obras mitográficas, Hércules animoso y La Psyche, junto a la poesía dispersa -tanto vernácula como latina- en la colección de la Biblioteca Castro (en prensa). En cuanto a la trayectoria profesional del humanista, véase FEDERICo SÁnchez y Escribano, Juan de Mal Lara. Su vida y sus obras, Hispanic Institute in the United States, New York, 1941. Por nuestra parte, acometimos un estudio del primer poema aducido en El mito de Psique y Cupido en la poesía española del siglo XVI, Universidad, Sevilla, 2002, pp. 77-169 y 203-218. Actualmente, preparamos una monografía, en fase avanzada, circunscrita al Hércules.

2 Para esta obra, cf. José LARa Garrido, La poesía de Luis Barahona de Soto (lírica y épica del manierismo), Universidad de Málaga-Diputación Provincial, Málaga, 1994.

${ }^{3}$ De interés es, en este sentido, el locus communis del catasterismo de la Hidra y el Cancro; véase Francisco J. Escobar, "Mas si me mira Calíope, diestra: la proyección del canon épico-mitográfico de Juan de Mal Lara en Fernando de Herrera”, en El canon en la poesía española del siglo XVI, ed. B. López Bueno, Universidad, Sevilla, 2008, pp. 332-334. 
Erato, en el caso de Herrera, bien en compañía de Calíope, en virtud del magisterio de Mal Lara.

Juan de la Cueva (1543-1612), por su parte, también consideró a Mal Lara un modelo, según se observa en distintos aspectos de su obra, tales como en sendas epístolas del Exemplar poético (II, 743-745 y III, 1800-1805 y 1632-1640) ${ }^{4}$. Por ello, el hecho de que Cueva valorase al humanista en calidad de auctoritas explicaría visibles paralelismos temáticos. Tiene lugar, en concreto, en un pasaje del Exemplar (epístola III, 1725-1736) que evoca un fragmento de La Psyche referido a $\mathrm{Momo}^{5}$. Esta relación intertextual denota, claro está, el vínculo que presentaban ambos autores con el teatro humanístico ${ }^{6}$. En lo que hace a Mal Lara, asistimos, en particular, a una escena en la que Momo participa junto a las Musas al tiempo que desfila una variada nómina de figuras estereotipadas de sesgo plautino: el viejo, el siervo o la dama desenvuelta ${ }^{7}$. El texto de Mal Lara fue imitado, como veremos, por Mosquera -amigo de ambos- en un contexto dramático-humanístico parejo: el prólogo a La famosa tragicomedia de Santa Catarina de Hernando de Ávila. En este juego de correspondencias, la codificación del personaje de Momo se muestra semejante en Mal Lara y Cueva; es decir, en La Psyche (XII, 153-158) aparece el dios del sarcasmo burlándose de la escena contemplada en el Parnaso de forma equivalente al Viage de Sannio (XII, 18) ${ }^{8}$.

${ }^{4}$ Además del soneto 57, Al doctíssimo maestro Iuan de Mal Lara, aviendo hecho una obra a la muerte de Orpheo: "Detened la sobervia padre Eólo / no sople viento refrenad su ira" (Biblioteca Colombina, 56-3-4; De las rimas..., f. 72v). Sobre este asunto, ofrecemos un análisis, desde el concepto de canon, en "Juan de la Cueva, artifex exclusus: un poeta en los «márgenes» del Parnaso sevillano, a propósito del Viage de Sannio", Actas del VIII Congreso de la Asociación Internacional del Siglo de Oro (AISO), eds. S. Fernández Mosquera y A. Azaustre (en prensa); y "La obra poética de Juan de la Cueva en el entorno sevillano (con un excurso sobre sus vínculos con Diego Girón y Fernando de Herrera)", Rivista di Filología e Letterature Ispaniche (en prensa).

${ }_{5}$ Personaje grato a Cueva en el Viage de Sannio, el Llanto de Venus y otras composiciones.

6 "Con estrañeza en todo as de mostrarte / admirable, vistiendo las figuras / conforme al tiempo, a la edad i al arte: / al viejo avaro enbuelto en desventuras, / al mancebo rabiando de celoso, / al juglar dezir mofas i locuras; / al siervo sin lealtad i cauteloso, / a la dama amorosa o desabrida, / ya con semblante alegre, ya espantoso; / a la tercera astuta i atrevida, / al lisongero enbuelto en novedades / i al rufián dar cédulas de vida" (citamos por la ed. de J.M. Reyes, Alfar, Sevilla, 1986, pp. 104-105).

${ }^{7}$ Los versos son los siguientes (XII, 159 ss.): "Él mismo [Momo] declaraua el argumento / del viejo que de auaro se moría; / del moço que en amor perdía el tiempo; / del sieruo que engañaua a sus señores; / y de la cortesana que embaía; / y del truhán en mesas desembuelto. / En fin, todas las vidas de los hombres / les puso en un theatro declaradas, / condenando lo más que en ello vía" (citamos conservando la ortografía original y regularizando acentos y puntuación).

8 "Y lo que más contento daua a todos / era venir el Momo, allí presente, / y ser juez de toda aquella fiesta. / Él se reía tanto de las cosas / que passauan en este gran theatro / que no dexaua quien riese dello". En cuanto al texto de Cueva: "Momo 
En la génesis de estos testimonios épico-mitográficos estuvo bien presente, en el marco de la Academia, Cristóbal Mosquera de Figueroa (1547-1610), otro de los celebrados contertulios allegado a Mal Lara, Herrera y Cueva ${ }^{9}$. Pero si el Divino se inclinaba por recorrer el camino de Erato -aunque sin olvidar las líneas matrices de sesgo épico-, Mosquera, en contraste, no se sintió nunca atraído por la epopeya. Con todo, el concepto de poema de Mal Lara exhibía una serie de características simbólico-alegóricas que tuvo en cuenta en su Enamorado Eliocriso, obra no conservada hasta la fecha, pero elogiada por sus coetáneos ${ }^{10}$. Además, varios de los elementos y recursos aplicados por Mal Lara en su visión de la épica humanística o erudita ${ }^{11}$ dejaron su huella en la poesía de su amigo, según habremos de analizar.

Sea como fuere, la relación entre Mal Lara y Mosquera fue palpablemente estrecha en el origen de tales empresas. Lo demuestra, entre otras cosas, la cercanía con la que se refiere Mosquera a los dos poemas mitográficos del maestro en el prefacio a la Descripción de la Galera Real, donde le rinde un sincero homenaje en virtud del Vaticinio de Proteo $^{12}$. Sabemos, en este sentido, que Mal Lara se encontraba próximo cuando se estaba forjando el Eliocriso, ya que en la Descripción nos

se ríe i dize: si te agrada / que no entre el que llama a tu aposento, / sea en buen ora, tenle aparejada / la oreja, i su razón escucha atento. / Viendo Sannio que no responde nada, / buelve a dezir en levantado acento: / ¡ó, Iove!, ¿¿ónde estás?, ¿por qué te ascondes / i a mis justas plegarias no respondes?" (ed.J. Cebrián, Miraguano, Madrid, 1990, p. 38).

${ }^{9}$ Sobre la obra del poeta sevillano, José León Gustá ha hecho su tesis doctoral, Mosquera de Figueroa: poesía completa, dir. por R. Navarro Durán (Universidad, Barcelona, 2001-02).

${ }^{10}$ Entre ellos, Baltasar del Alcázar en su poema Al "Eliocriso" de Cristóbal Mosquera, Herrera en las Anotaciones y Francisco Pacheco en el Libro de descripción de verdaderos retratos.

11 Véase, para un desarrollo de esta cuestión, Francisco J. Escobar, "La forja del canon épico en la Academia de Juan de Mal Lara (con unos versos desconocidos de Fernando de Herrera)", Studia Aurea, 1 (2007), 1-33. En esta concepción del poema simbólico por parte de Mal Lara y Mosquera jugó un papel destacado la novela griega. De hecho, el primero tuvo en propiedad un ejemplar del relato del siglo XIII, Hismines e Hisminia, obra de Eustacio Macrembolita y que había sido traducido al italiano por Lelio Carani en 1550. Este volumen fue vendido en pública almoneda a la muerte de Mal Lara, y Mosquera lo adquirió; véase MAnuel Bernal, "La Biblioteca de Juan de Mal Lara", PHisp, 1989, núm. 4, p. 399.

${ }^{12}$ Figura recreada en La Psyche, XI, 793 ss. El pasaje de Mosquera es el siguiente: “...en el diuino Hércules, que con tanta fertilidad de estilo eroyco descriuió sus doze trabajos en quarenta y ocho cantos, donde tanta historia de antiguos capitanes y señalados varones, y tanta philosophía natural y moral se esparze y resplandece por ellos. Escriuió otro uolumen de la hermossíssima Phsyche, por cuios amores ardió en su mesmo fuego Cupido, mostrando en rima suelta muchas estrañezas y variedad que aumentaron la gracia y perfección desta fabulosa historia, llena de admirable suauidad" (cf. Juan de Mal Lara, Recebimiento. Descripción de la Galera Real, ed. M. Bernal, Fundación José Antonio de Castro, Madrid, 2005, p. 172). 
indica que en 1568 tuvo en su poder este poema ${ }^{13}$. De la misma forma, el desarrollo creativo del elogio paradójico por parte de Mosquera ha de corresponderse con otros recursos retóricos similares empleados por Mal Lara en su producción mitográfica. En fin, por los claros paralelismos existentes en el corpus de ambos hombres de letras, consideramos de rigor dedicar las páginas que siguen a esta cuestión.

\section{PARALELISMOS TEMÁTICOS EN LA OBRA POÉTICA de Mal Lara y Mosquera de Figueroa}

En el contexto literario trazado, cabe constatar, en lo que al plano de la tradición retórica se refiere, la pervivencia del encomio paradójico tanto en la épica humanística de Mal Lara como en el corpus poético de Mosquera ${ }^{14}$. La razón responde -al margen de ser una práctica conocida en el ámbito de la Academia- al hecho de que el autor del Hércules había reflexionado, desde postulados teóricos, sobre variadas fórmulas para el elogium y la vituperatio, en concreto, en los In Aphtonii Progymnasmata Scholia de $1567^{15}$. Sobresale, además, en este cuadro de procedimientos técnicos, la propuesta de un canon de poesía espiritual por parte de Mal Lara, a tenor de sus composiciones contenidas en la Mistica pasionaria y el cancionero mexicano colectivo, Flores de baria poesía (1577) ${ }^{16}$, afín a la que se descubre en Mosque-

13 "Aunque en el huerto de las Hespéridas se ha de tratar deste árbol, pero porque aquí son menester sus ojas y cohollos, que con la hermosa flor del azahar dan tan suaue olor y graciosa vista que es tenido por el mejor árbol de todos (como Cristóval Mosquera de Figueroa lo encaresce en pocas palabras, en su Enamorado Eliocriso, que tuue en mi poder el año de MDLXVIII en el libro primero)..." (MAL LARA, "Del naranjo. V”, en Descripción de la Galera Real, ed. cit., pp. 330-331).

14 Aunque disociado de este género. En el caso del autor del Hércules, se distingue la defensa de los afeites en La Psyche por una desenvuelta dueña; véase FrANcisco J. Escobar, El mito de Psique y Cupido..., pp. 130 ss. Sobre la vigencia de este procedimiento retórico en Mosquera, cf. VALENTín Núñez, "Para la trayectoria del Encomio paradójico en la literatura española del Siglo de Oro. El caso de Mosquera de Figueroa”, Actas del IV Congreso Internacional de AISO, Universidad, Alcalá, 1999, pp. 1133-1143, y Mosquera de Figueroa y el elogio burlesco. Paradojas en loor de la nariz muy grande y de las bubas, Universidad, Salamanca (en prensa).

15 Constituye un tratado con paralelismos y divergencias respecto al acometido por su maestro Francisco de Escobar (Aphtonii sophistae progymnasmata, Barcelona, 1558). Ha sido analizado en sendos artículos por Trinidad Arcos y María E. Cuyás ("Los comentarios a los Progymnasmata de Aphtonio de Escobar y Mal Lara: estudio preliminar”), así como por M. Dolores García de PAso y Gregorio Rodríguez ("Los Comentarios de Reinhardus Lorichius y Juan de Mal Lara a los Progymnasmata de Aftonio: una aproximación”), ambos en IV Congreso Internacional de Humanismo y pervivencia del mundo clásico. Homenaje al profesor Antonio Prieto, eds. J.M. Maestre et al., Universidad de Cádiz-Instituto de Estudios Turolenses, Alcañiz-Cádiz (en prensa).

16 Pueden leerse estas composiciones en nuestra edición de la Biblioteca Castro. 
ra. Desde este prisma, poemas como En loor de la santísima cruz, A los dulces clavos que hincaron a nuestro Señor Jesucristo o A la sagrada coluna en que fue nuestro redenptor Jesucristo azotado manifiestan no sólo un patente recuerdo de la Mistica pasionaria, a modo de amplificatio de escenas diseminadas, sino también un conocimiento cabal de las técnicas retóricas expuestas de forma teórica por Mal Lara ${ }^{17}$ y llevada a la praxis creativa en sus poemas mitográficos. Se comprueba, especialmente, en los exempla mythologica circunscritos a Hércules y diversos personajes.

Por otra parte, el contenido teológico con referencias a la Trinidad, el íntimo vínculo simbólico de Cristo con la Iglesia -como institución que difunde su doctrina- y complejas cuestiones recreadas por Mosquera en calidad de "misterios" constituyen enclaves parejos a la espiritualidad emanada de la cosmovisión de Mal Lara como formación dogmática. Así lo ilustra el tratado del teólogo Juan Ochoa (Omnes primariae conclusionis omnium et singulorum articulorum, partium diui Thomae additionumq[ue]: quibus titulis quaerentibus respondetur, in carmen redactae, quo facilius memoriae mandare possint / autore..., Antonio Blado, Roma, 1565), en el que colaboró nuestro humanista, en calidad de auctoritas, con un epigrama: Ad Modvm Reverendo Patri Ioanni Ochoae Sacrae theologiae Magistro. Professori instituti Sancti Dominici Montis Syon nunc priori, in Epitomen Diui Thomae Aquinatis. Ioannes Mallara (ff. 3r-3v) ${ }^{18}$. Es más, al igual que hace Mal Lara en su épica mitográfica, Mosquera conjuga la vertiente cristiana con el canon pagano, según se ve en el poema $A$ los dulces clavos..., mediante una imbricación de alusiones mitológicas -como la que atañe a Ifigeniay varias de sesgo bíblico. En este camino de perfección espiritual, sea el que recorren Psique y Hércules o, en un tratamiento literario parejo, Cristo en su pasión, consta siempre, como un principio cardinal, la virtus, en una confluencia con la lectura de abolengo estoico. Con esta intencionalidad procede, en consecuencia, Mosquera en A la túnica virginal que fue tejida por la S. ${ }^{a}$ madre para Jesucristo nuestro Señor, en A la sagrada coluna en que fue nuestro redenptor Jesucristo o A la cruel lanza que abrió el costado de Jesucristo nuestro Señor.

Otros recursos manejados por Mal Lara en su épica mitográfica son compartidos por Mosquera. Entre éstos despunta el símil de abolengo épico -a la manera de Homero y Virgilio- pero revestido de filosofía natural, al igual que lo concibe nuestro humanista. Resulta

17 Entre ellas, despunta, con claridad, el recurso del elogio.

${ }_{18}$ Dos ejemplares de tal edición custodia la Biblioteca General Universitaria de Sevilla con las signaturas: A Res. 28/5/16 y 30/7/06 (este último mútilo de portada). La edición y estudio de dicho epigrama latino lo ofrecemos en "La poesía dispersa de Juan de Mal Lara: una formulación estética entre latín y vernáculo (con nuevas noticias biográfico-literarias)", Silva. Estudios de Humanismo y Tradición Clásica, 2007, núm. 6, 119-153. 
perceptible en A la sagrada coluna en que fue nuestro redenptor Jesucristo, con apuntes, por añadidura, a Vulcano y los cíclopes, como en $L a$ Psychey en el Hércules ${ }^{19}$. En lo que atañe a su héuresis interna -con una microestructura de por medio-, tales versos rememoran los del libro segundo de La Psyche (vv. 21-29) ${ }^{20}$. Asimismo, las apelaciones al lector, de forma parecida al aliento épico de Mal Lara, las emplea Mosquera en fórmulas como "veréis luego". En consonancia con esta voluntad estética, se distingue, consecuentemente, un ejemplo de evidentia desde la perspectiva del afligido, en actitud análoga a Psique, al mover a compasión y llanto "en su apartamiento retirado". Asistimos, pues, a una palmaria recreación del si vis me flere horaciano, conjugada con la consabida tópica estoica del seccessus o la seccessio ('retiro'). Y claro está, la imagen de la sagrada columna sugiere a Mosquera la mítica fundación por parte de Hércules -emblema simbólico de Sevilla-, en un homenaje al maestro y a su célebre poema, del que fue excelente testigo y colaborador ${ }^{21}$. Los motivos de la catábasis o del Estrecho están presentes, justamente, en el Hércules:

Cubra la antigüedad supersticiosa en las profundas aguas del Leteo del griego Alcides los trabajos grandes de poetas heroicos celebrados; con coronas y sombras de virtudes que $\mathrm{a}[\mathrm{h}]$ uyentando males de la tierra después que fue por ella peregrino dejó de sí memoria, levantando las dos grandes colunas como término del limitado mundo junto al agua del grande océano, a la parte llamada estrecho de Hércules, con letra (non ultra) no hay pasar más adelante. Huyan, huyan los sueños fabulosos las sombras y fantasmas de poetas que quien pusiera en ti, coluna ilustre denotó el pensamiento y dedicara a la memoria suya sus trabajos

19 "Luego que fue desnudo con la soga / la coluna abraçando, lo rodean / y como mansa oveja en la presencia / del pastor, que en el marco le despoja / de la lana y vellón con la tijera / y le dexa volver de un lado y otro / sin hazer resistencia ni quexarse. / Así se dexó atar del hombre fiero / su Dios y su criador de su criatura..." (cf. Mosouera de Figueroa, Obras, t. 1: Poesías inéditas, ed. G. Díaz-Plaja, Real Academia Española-Biblioteca Selecta de Clásicos Españoles, Madrid, 1955, p. 71).

20 "Y assí quedó la triste Psyche sola, / según quando la oueja acompañada / antes de su pastor y del ganado, / que cubre todo el campo su desdicha, / la hizo quedar sola y oluidada, / tonta que se repara cien mil vezes / y buelue la cabeça a todas partes, / dando un balido flaco y más si teme / la noche y oye los lobos cómo aullan...”.

${ }^{21}$ De hecho, es mencionado en el poema mismo. 
y de aquel gran dolor se condoliere, esté seguro que tendrá más premio más fama, más renombre, y mayor gloria que todos los Alcides que en historias de Griegos y Latinos se celebran y contigo entrará tan poderoso que no sólo penetre mar y tierra pero pondrá el plus ultra allá en el cielo y con el tuyo vivirá su nombre ${ }^{22}$.

En el texto, el leitmotiv de los "poetas heroicos" conlleva una referencia metadiscursiva al género épico -e implícitamente a Mal Laracomo medio de canonización. En este sendero, la divisa del plus ultra evoca, una vez más, el Hércules, en concreto, el canto XII, 1, 545-55223. Desde este distintivo, la insignia patriótica bosquejada, con la mención manifiesta de España, la viene a aplicar, a la par, Mosquera en $A$ don Alfonso Pérez de Guzmán, el bueno, duque de Medinasidonia ("nuestra fértil Hespaña a los varones"). Se trata, por ende, de una reminiscencia de las galerías de nobles diseminadas por Mal Lara en sus poemas mitográficos. En esta confluencia de registros y tonos, en el Soneto a doña Juana de M. luce, además, otro apunte a Alcides: "Tú serás otro Alcides o Medoro / que por el alto premio de la gloria / venció trabajos y domó el profundo" (vv. 9-11) ${ }^{24}$. De forma similar sucede en la pieza A la escalera con que bajaron de la cruz a Iesuchristo $\mathrm{Nr}^{\circ}$ redemptor mediante un circunloquio dedicado al tratamiento de Alceo y su nieto Hércules por Mal Lara ${ }^{25}$.

Junto al emblema del fundador de Sevilla, la invocatio a la Musa, habitual en las obras mitográficas de Mal Lara -conforme a la tradición literaria desde Homero, Apolonio o Virgilio-, se hace visible en A la cruel lanza... ("Rompe Musa divina, da lanzada") ${ }^{26}$, en tanto que el recuerdo de Teseo en la Epistola de Lucinda a Medoro de Mosquera entronca con el interés por este personaje en el Hércules (es el caso de

${ }^{22}$ Ed. cit., p. 81.

23 "Los mármoles que vieron allá eminentes, / donde la Magestad su ysla tiene, / allí los mira puestos y presentes. / Corona d'oro cada qual sostiene, / dando la Fama bueltas diligentes. / En medio dellos, puesta Hespaña viene. / Afírmanse, delante, un cauallero / y Plus Ultra tenían por letrero".

24 Ed. cit., p. 185.

25 “...no tenga parte aquí la humana ciencia / ni de aquel nieto del famoso Alceo / que tuvo por trofeo / cargar en su cerviz el rutilante / cielo, que agora oprime la de Atlante, / que sola esta escalera ha sustentado / al Sumo Hacedor de lo criado" (ed. cit., p. 95). El motivo queda explicado por Mal Lara en la entrada pertinente del Hércules: "ALCEO. El auuelo de Hércules, de adonde se dixo Alcides; o es nombre fingido de un pastor de Arcadia, puesto por un amigo del autor que començaua assí el nombre verdadero [seguramente D. Álvaro de Portugal, conde de Gelves]".

${ }^{26}$ Ed. cit., p. 83. 
XI, 4). En tan definida recuperación del imaginario clásico, el pasaje de Belerofón y Pegaso -correspondiente al libro sexto de la Ilía$d a-$, con huellas en Hércules, II, 4, constituye la piedra angular para Mosquera en el Soneto al señor Pedro de Pineda Caballerizo de la orden de Calatrava. Caso análogo acaece con el detalle que atañe a la fábula de sesgo mítico, de considerable relieve en la concepción de épica humanística por Mal Lara; de hecho, está presente, como paralelo, en la In encomium pacis ode. Al rey don Filipe Tercero nuestro Señor siendo Príncipe de Mosquera. De otro lado, en esta inclinación por el sermo sublimis -según se ha señalado para la epopeya homérica-, la remembranza de la Eneida (VI, 268-272), a propósito de la noche que impregna el espacio de oscuridad ${ }^{27}$, deja su huella en unos versos del poema $A$ la escalera...: "y ya la oscura noche había tendido / su negro manto..."28. Finalmente, en equilibrio con el imaginario pagano, tiene cabida, en armonía y concierto, la doctrina cristiana en virtud del motivo de la piedad (en A la escalera..., ibid., p. 91). de notorio predicamento en los epigramas de Mal Lara.

Por otra parte, Mosquera esboza una táctica parecida de autocanonización mediante la imagen, a la manera de Mal Lara ${ }^{29}$, en el Soneto al retrato del licenciado Mosquera de Figueroa pintado de mano de Mateo Pérez de Alecio. En consonancia con esta práctica retórica, se justifica, por consiguiente, el encomio consagrado a Jerónimo de Carranza -quien colaboró, por cierto, en las obras mitográficas del humanista- en el poema titulado Al libro de las armas de Gerónimo de Carranza. Elogio. Emplea Mosquera, en fin, un mecanismo cercano al del Hércules $^{30}$ en aras de ensalzar esta figura singular en el dominio de las armas y las letras. Se observa en el canto V, 4, 25-56:

Quién dirá dónde mira tal mudança

con tal ayre mouer la presta espada,

espada qu'era sólo de Carrança

y dél, quando la mira antes dudada, aquella nueua gracia y su templança de quando ha de formar rezia estocada, estocada a la qual no auía reparo, porque se vía el peligro, luego, claro.

27 "Ibant obscuri sola sub nocte per umbram / perque domos Ditis uacuas et inania regna: / quale per incertam lunam sub luce maligna / est iter in siluis, ubi caelum condidit umbra / Iuppiter, et rebus nox abstulit atra colorem" (citamos el texto por la ed. de R.A.B. Mynors: P. Vergili Maronis Opera, Oxford University Press, Oxford, 1969, p. 235).

${ }^{28}$ Ed. cit., p. 93.

29 Como hace nuestro humanista en un epigrama consagrado al retrato que le dedicó Juan Bautista Vázquez en los Progymnasmata; cf. Francisco J. Escobar, "La poesía dispersa de Juan de Mal Lara...", pp. 133 ss.

${ }^{30} \mathrm{Y}$ en un preludio, a su vez, del Libro de retratos de Pacheco. 
El poco miedo con que se exercita y la razón que da, porque no tiene pauor ante'l qu'esfuerço a todos quita y qualquiera a rrendir su espada viene, que libertad, que almas libre limita y haze su deuer quando conuiene, aquel salir de todo defendiéndose y con todo buen punto recogiéndose;

¿con qué inuidia miraua Marte, ayrado, los tajos y reueses pressurosos? Contra el autor de todo está enojado. Gemidos de su pecho congojosos sacaua, quanto puede él enfadado de los hombres, que son tan animosos. ¿Veys (dize) qué me queda en las batallas, si gentil duque en ellas oy te hallas?

¿Quién t'enseñó que auía el hombre diestro?

Bastárale su fama y sus razones quanto le daua el mundo de maestro, poniendo mi furor en ocasiones. ¿Qué hado vino a Thracia tan siniestro que usurpen en Iberia sus pendones? De Carrança las armas están puestas. Las mías van al suelo descompuestas

No menos alabanza recibe Fernando de Herrera de la mano de Mosquera en un soneto panegírico dedicado a éste. En un proceder próximo a Mal Lara en el Hércules, enfatiza nuestro poeta, de forma elativa, las cualidades del laudandus, su caro amigo. Especial calado merece, entre otras cosas, la mención metadiscursiva consagrada al término "retrato" por parte del laudator ${ }^{31}$. Por último, en paralelo a estas huellas intertextuales, centraremos nuestra atención en el estudio de un motivo temático ensayado por Mal Lara, partiendo de la inserción de elementos del teatro humanístico en escenas de sus poemas mitográficos ${ }^{32}$. Éstos, por ende, habrían de dejar su estampa en el prólogo de Mosquera a La famosa tragicomedia de Santa Catarina de Hernando de Ávila, estrenada entre 1596 y $1597^{33}$. Veámoslo.

31 "En medio de él se muestra la figura / de la inmortalidad que prevalece / y entre los altos Dioses lleva palma / Retrato de la inmensa hermosura / que, divino Fernando, resplandece / en el sagrado templo de tu alma” (ed. cit., p. 198).

${ }^{32}$ De esta suerte, se producía cierta neutralización genérica.

33 Una edición de este preliminar -por la que citaremos- ha propuesto José León Gustá, "El prólogo a la famosa tragicomedia de Santa Catarina de Cristóbal Mosquera de Figueroa”, Salina, 2004, núm. 18, 91-110. 
En efecto, en la referida conjugación de canon pagano y cristiano, Mosquera, en el arranque de dicho proemio, refunde varios pasajes del Hércules y La Psyche. Así, en el desenlace de La Psyche (XII, 123-189) y alejándose del Asinus aureus de Apuleyo, Mal Lara bosqueja, a modo de theatrum mundi, un Parnaso en el que cada una de las Musas, presentadas en un catálogo, encarna, de forma metadiscursiva, el género que simboliza, en compañía de Apolo $^{34}$. En síntesis, se ofrece, en este pórtico de entrada, una nutrida relación de personajes de carácter plautino -en una suerte de contaminación-, acordes con el teatro humanístico cultivado por Mal Lara. Talía, en concreto, "da principio a mil comedias" (XII, 150) que relatan los proteicos paradigmas de vida de los hombres. En este contexto irrumpe, además, la figura de Momo actuando como "juez" en el alegre thea$t r o^{35}$, sin permitir reír a los asistentes. Como si se tratase de la puesta en escena de una comedia plautina, este sombrío personaje hace las veces de Prologus en tanto que explica al público el argumento de los personajes que intervienen en el "theatro alegre": el viejo avaro, como el Euclión de la Aulularia; el joven enamoradizo, a la manera de Calidoro en Pseudolus; el servus fallax ${ }^{36}$; la meretrix, en el Truculentus; y el parasitus, que come sin trabajar, según se ve en el Curculio ${ }^{37}$.

Mal Lara se está refiriendo, claro está, no sólo a los estereotipos de Plauto, sino también al teatro universitario de la época, género con el que el humanista estaba plenamente familiarizado ${ }^{38}$. Esta vertiente literaria, redactada en latín, romance o en ambas lenguas (normalmente en verso), con personajes alegóricos y con un valor educativo y

34 Véase Francisco J. Escobar, El mito de Psique y Cupido..., pp. 146 ss.

${ }^{35}$ La utilización del vocablo theatro por Mal Lara da la clave para interpretar las escenas dramático-alegóricas de La Psyche. Así pues, lo emplea en sentido literal ('lugar de representación') y figurado.

36 Tal es el caso de Tranión en Mostellaria.

37 Gorgojo actúa como un parásito de Fedromo.

${ }^{38}$ Pese a que no se conservan sus obras dramáticas, se deduce, mediante testimonios indirectos, que Mal Lara realizó un teatro de corte humanístico conocido, seguramente, desde su etapa en la Universidad de Salamanca, donde se representaban piezas plautinas. Al autor de La Psyche se le atribuyen, entre otras piezas, las tragedias Absalón y San Hermenegildo, las comedias Elogio de nuestra Señora de la Consolación de Utrera y Locusta, así como las églogas Laurea y Narciso. A esta relación cabe añadir la tragicomedia Achiles hallado, anterior a 1565. El dato lo brinda Mal Lara en la entrada Achiles de la tabla del Hércules: “...hijo de Peleo y Thetis, diosa de la mar, que fue dado a criar a Chirón, centauro, en el monte Pelio, y se crió en hábito de muger en Scyros, en casa del rey Lycomedes, adonde lo hallaron Vlixes y Diomedes de que ay dos libros en Stacio llamada Achileis y el autor tiene hecha una tragicomedia que se llama Achiles hallado ...". Consta, por añadidura, una concisa noticia sobre una tragedia de nuestro humanista en las Actas Capitulares de la ciudad hispalense (14-VII-1570): "El cabildo otorga licencia «para que en esta sancta iglesia se represente la traxedia de Malara y sea el día que el señor doctor Isidro de la Cueva ordenare a quien se le comete el negocio con tanto que de la fábrica no se gaste dinero alguno»" (ACS, sección I, vol. 30, f. 47v). 
moral, ofrecía la representación de obras de materia clásica ${ }^{39}$, religio$\mathrm{sa}^{40} \mathrm{y}$ popular. Las comedias solían comenzar con un prólogo -en la línea que lo concibe Mosquera-, a cargo, con frecuencia, de un personaje que declaraba el argumento ${ }^{41}$, al tiempo que ostentaban un coro, aquí presidido por las musas. En este marco alegórico, disfrutamos, por tanto, del "teatro dentro del teatro" mediante el metadiscurso o lectura de segundo grado, a saber: la Comedia y la Tragedia actúan como tales personajes y son censuradas por Momo, objeto de burla, a su vez, de los allí presentes ${ }^{42}$. Por otra parte, esta escena se erige como una más de las que Mal Lara denomina theatro en La Psyche, en una suerte de neutralización genérica. En virtud de ésta, el artífice adoctrina al lector presentándole la enseñanza de manera visual y atractiva. El pasaje es el siguiente:

Con gran honestidad sus manos [las Gracias] dauan; y passando delante, aparesciera un monte leuantado con dos cumbres donde fuentes manauan dulcemente con árboles y flores reuestido. Parnaso era, según se descubría un assiento dorado en donde estauan nueue donzellas todas, nueue hermanas qual mueue con su lengua a todo el mundo, qual con sus instrumentos, suauemente, haze parar los hombres sin sentido. Otra los mouimientos celestiales declara y otra llora, en alto canto, la caýda de príncipes notable.

Ninguna estaua ociosa; y reparando ante la naue, el monte se presenta en un breue momento quanto historias tienen en sus escriptos encerrado. Allí los valerosos capitanes tenían su loor y su triumpho; y daua Apolo a esto, luego, el cuerpo que, quando se contaua en aquel punto, passaua por delante todo en forma de lo que acontesció quando ello fuera. Vio Psyche grandes cosas desde quando

${ }^{39}$ Con predominio de Terencio, Plauto y Virgilio.

${ }^{40}$ Sobre todo, de inspiración bíblica, al igual que la Tragicomedia que nos ocupa.

${ }^{41}$ Como hace en este pasaje Momo.

${ }^{42}$ En el Viage de Sannio - con loci communes respecto al Eliocriso de Mosquera-, Cueva aprovecha también la narración alegórica para llevar a cabo unas consideraciones literarias sobre la comedia y la tragedia (ed. cit., pp. 109 ss.). Momo, a quien Cueva le dedica una epístola inserta en los preliminares de la Primera parte de sus Comedias y Tragedias, será el juez de la poesía de Sannio (ed. cit., pp. 117 ss.). 
el mundo començó hasta aquellas horas.

Assí como acabó Clío sus obras,

Thalía dio principio a mil comedias

de quanto en este mundo representan

los hombres de costumbres variadas.

Y lo que más contento daua a todos

era venir el Momo, allí presente,

y ser juez de toda aquella fiesta.

155

Él se reía tanto de las cosas

que passauan en este gran theatro

que no dexaua quien riese dello.

Él mismo declaraua el argumento

del viejo que de auaro se moría;

del moço que en amor perdía el tiempo;

del sieruo que engañaua a sus señores;

y de la cortesana que embaía;

y del truhán en mesas desembuelto.

En fin, todas las vidas de los hombres

les puso en un theatro declaradas, condenando lo más que en ello vía.

Luego salió Melpómene, más alta, con género de ropas más costosas, con el cothurno rico y real lengua.

Momo le dixo: "también viene la Muerte sobre los chapiteles de los reyes como sobre las casas de pastores.

Andad, que todo llora en esta vida”.

Assí, desta manera Euterpe vino

y la dulce Terpsícore con flautas, con vihuelas mouiendo los affectos.

Erato, l'amorosa, en el serao

no menos tuuo gracia con su andanza.

Con su cantar en tono requebrado,

Urania razón daua del cielo, aunque Momo le dixo quánto auía que descindiera dél. Y, luego, llega

Polyhimnia, eloquente en todas lenguas.

Dales el parabién del matrimonio.

Calíope fue dellos rescibida,

según gouernadora de las Musas;

y consigo traía al buen Orpheo,

el qual cantó, según solía en Thracia.

De forma similar, Mal Lara, en el Hércules (IV, 1), retoma el motivo, pero, en esta ocasión, a partir del canto de Orfeo, inscrito en el texto precedente (vv. 188-189). Tampoco enfatiza, en contraste, el carácter y marco teatral de la escena. Esta variatio obedece, no obstante, a que la funcionalidad del poema viene a ser distinta -pese al 
vuelo épico de ambas obras-, puesto que se trataba de realzar el efecto mágico de la música. Por ello, despuntan, más bien, las invocaciones, en virtud de la fórmula hímnica $h u c$ ades $^{43}$, a fin de recrear el tópos del praesens deus:

Iasón muy demudado, con desseo de ver su voluntad puesta en efecto, con los más de los otros, mira a Orpheo como si en él uuiera algún secreto, que tome harpa en mano el Caliopeo 685 y, mueua la galera en tal aprieto.

Él la tomó, tañendo, con su verso, la más dulce canción del Universo:

"Musas, que de la sacra Mnemósyne y del antiguo Iúpiter nacistes, vuestro fauor, vuestr'aura me encamine, pues que mi $[\mathrm{sic}]$ justos votos siempre oistes; o Clío, en las hazañas boz insine. Melpómene ven. Dexa casos tristes. Terpsíchore, tú bayla en esta dança. Ven tú comigo, Euterpe, a la mudança.

Erato, con tus cantos amorosa, alegre en tus comedias. Ven, Thalía.

En razonar, Polymnia, poderosa. Danos saber del cielo, o Uranía. Y tú, que eres a boz dellas hermosa, en más sublime grado y madre mía, Calíope, descubre tus cabellos, que vea yo luzir mi luz por ellos.

Pues que me diste aliento que baxasse, por mi bella Eurýdice, a la laguna, donde Charón, el cano, me passasse, y no me resistiera vena alguna, que todo con mis rimas se ablandase; Prosérpina me dio ley de fortuna. Queriendo con mi amor adelantarme, vine con sombra triste a consolarme.

Pues bien, Mosquera, en el arranque del prólogo a La famosa tragicomedia, reelabora, bajo el prisma del teatro humanístico, tal núcleo temático codificado en los poemas de Mal Lara. Aducimos, en pri-

${ }^{43}$ Que habrá de retomar Mosquera, según veremos, para su pasaje. 
mer lugar, el texto en cuestión en aras de que se pueda cotejar con los pasajes analizados:

El rojo Apolo y las hermanas nueve que en el sagrado monte de dos cumbres en torno la divina fuente cercan, y bañando los labios en sus ondas con voces y instrumentos acordados hace del monte cielo su armonía; Tersícore, que mueve los afectos que causa el blando toque de las liras; Euterpe, que con mano artificiosa entona regalados instrumentos: déjenlos para el fin de aquesta historia, cuando vierdes salir la blanca leche del blanco cuello de la tierna virgen y vieren recebir el alma santa (...). A ti llamo, Melpómene admirable, que con el verso y trágico ornamento autorizado en hábito y palabras diste espíritu a Sófocles y a Séneca, ambos gloria de griegos y latinos.

Y a ti, Talía, que ha de ser forzoso tomar alguna parte de tu estilo, porque aquel gozo que las almas mueve a mostrar por de fuera sus afectos de manera ha de ser que nos obligue a usar de algunos cómicos discursos: vuestra virtud socorra a mis conceptos. Escúsase el autor desta tragedia, -si no es tragicomedia la que oyerdesde usar del argumento separado como en puras comedias se acostumbra. Porque si queréis verlo brevemente, aunque es un claro espejo la comedia que representa nuestra humana vida, difiere de tragedia en el estilo, en traje y condición de las personas. Aquí no trataremos de Pármenos, de Davos, ni de Taides, ni serviles Eunucos, ni de astucias de criados, de gula de truhanes, ni de robos a flacos viejos, ni fingidos nombres de juegos, ni mancebos distraídos, ni trazas verisímiles que forman un argumento o fábula ordenada: que la tragedia antigua era un sujeto no desconforme a la virtud heroica 
adonde se introducen grandes príncipes,

famosos y guerreros capitanes,

ciudades y castillos arruinados,

desmantelados muros, hierro y sangre,

muertes y parricidios y destierros,

incendios, epitafios y funestas

exequias, llantos mensajeros tristes.

Pues en la Antigüedad supersticiosa

con representación grave y calzado

bajaban de los cielos estrellados

a sus fingidos dioses, y salían

de los cuatro elementos las deidades...

Las concomitancias entre este fragmento y los de Mal Lara resultan, según se puede comprobar, harto visibles. En el texto de Mosquera, sus elementos míticos -recreación del espacio y de sus personajes-actantes, vv. 1 ss.-, la intencionalidad metadiscursiva ${ }^{44}$ junto con la llamada a éstas a modo de invocatio (vv. 26 ss.), la presentación de atributos simbólicos, como los relativos a la indumentaria (vv. 46, 65), o el catálogo de personajes tópicos en la línea plautina (vv. 47 ss.) conforman la sutil armonización de ambos pasajes forjados por Mal Lara. Quedan ausentes, empero, otros protagonistas puntuales como Orfeo o Momo ${ }^{45}$.

Con todo, aunque exista una granada tradición en lo que concierne a la tópica (es el caso de Garcilaso, Égloga, III, 29), el diseño conjunto de las células temáticas aducidas apunta a que Mosquera, cercano lector de Mal Lara, armonizó ambas fuentes mediante una sutil reelaboración en el marco del teatro humanístico ${ }^{46}$. De esta suerte, abogaba por una reescritura del tópos, distanciándose, por ende, de la propuesta garcilasiana. Ello no impide, por último, que la referencia a la tragedia de Sófocles y Séneca (vv. 29-30), en el pasaje de nuestro poeta ${ }^{47}$, seguramente encuentre su correlato en la loa de Alejandra (vv. 3-9), de Lupercio Leonardo de Argensola, quien alude, por su parte, a Eurípides y Sófocles ${ }^{48}$.

En síntesis, alejado de la vida cultural que había hecho posible Mal Lara -desaparecido hacía años ${ }^{49}$-, Mosquera debió evocar, con nostalgia, tal etapa de antaño al calor de la Academia de Mal Lara.

44 Materializada en el apunte simbólico de las Musas con que alude a su dominio artístico (vv. 7 ss.).

45 Este último de evidente vigencia en la obra de Cueva, quien se inspiró en el Parnaso del Hércules animoso para el suyo presente en el Viage de Sannio.

46 Ya implícito, al menos, en el pasaje de La Psyche.

47 Ausente en los fragmentos aducidos de Mal Lara.

48 Hipótesis sugerida por José León Gustá, "El Prólogo a la famosa...”, p. 28, n. 30.

49 Mientras que la Tragicomedia se estrenó, según se ha indicado, entre 1596 y 1597. 
Coincidía dicho período de floruit intelectual hispalense con el nacimiento de obras de visible fuste y calado como los poemas épico-mitográficos de Mal Lara, sus valiosas aportaciones al teatro humanístico o la Descripción de la Galera Real (en este sentido, veremos, más abajo, los paralelos textuales compartidos por los amigos). Su actitud no resulta extraña, ya que si la concepción de épica erudita forjada por Mal Lara no influyó de un modo esencial en su tránsito por los senderos de Calíope, sí la tuvo en cuenta al codificar motivos tematológicos en su forma mentis literaria. Resulta perceptible, en efecto, tanto desde una lectura del imaginario pagano -de interés es, a este respecto, la presencia de Hércules-como en virtud de la doctrina cristiana, en consonancia con la Mistica pasionaria y otros poemas religiosos, en calidad de una poética culta. Por ello, Mosquera, en su proemio a $L a$ famosa tragicomedia -que conjugaba ambas vertientes-, decidió recuperar, en fin, la memoria de Mal Lara, a modo de homenaje, en unas circunstancias bien lejanas de ese anhelo de canonización que observara alguna vez el humanista en su propuesta estética de canon épico.

Ahora bien, sin duda, al margen de tales paralelismos -fruto de un ambiente literario compartido en la Academia hispalense-, mayor interés reviste el estudio de un manuscrito, custodiado en la Biblioteca del Castillo de Perelada, que unió, por avatares de la tradición textual, una parte de la obra de estos ilustres escritores sevillanos.

El códice R-49481 de la Biblioteca del Castillo de Perelada: UNA NUEVA FUENTE TEXTUAL PARA LA DESCRIPCIÓN DE LA GALERA REAL

En el marco bosquejado sobre los vínculos entre Mal Lara y Mosquera, cabe destacar, como un notorio capítulo, la relevancia de una nueva fuente para el estudio de la Descripción de la Galera Real ${ }^{50}$. Ésta arroja luz sobre la tradición textual de tan señera obra con vistas a una edición crítica. De hecho, hasta el momento, los investigadores, en su acceso a la Descripción, han venido manejando un manuscrito colombino apógrafo, lleno de errores. Sin embargo, antes de adentrarnos en este asunto, procede señalar, en un preceptivo pórtico contextualizador, que estamos ante el proyecto circunscrito al exorno de la Galera Real de D. Juan de Austria para la batalla de Lepanto. La Descripción fue concebida, fundamentalmente, por Mal Lara

50 Debo el conocimiento de esta fuente al entrañable maestro Alberto Blecua, quien me facilitó generosamente los datos al formar parte del tribunal evaluador de mi tesis doctoral. De otro lado, José León Gustá, en su estudio citado (Mosquera de Figueroa: poesía completa), ha manejado el ms. R-49481 de Perelada para la enmarañada tradición textual de Mosquera. Actualmente, llevo a cabo un estudio y edición crítica de la Descripción. 
aunque debió contar, al igual que en otras obras suyas como el Hércules o el Recibimiento de Sevilla a Felipe II, con una labor de grupo liderada por él en el ámbito de su Academia. La obra presentaba, a modo de preliminares, la Prefación y el Vaticinio de Proteo al Sermo. Sr. don Juan de Austria antes de que sucediesse la batalla naval, de Mosquera.

Como se ve, el díptico paratextual de Mosquera constituía un mecanismo de canonización del humanista. Desgraciadamente, ni Mal Lara ni sus coetáneos pudieron contemplar publicada la notable empresa, y permaneció inédita hasta el siglo xIX.

En efecto, el texto manuscrito de la Descripción que se ha venido editando hasta la fecha lo custodia la Biblioteca Colombina de Sevilla con la signatura 84-2-33. En este caso, contamos con una copia coetánea de la obra, preparada, como tantas de Mal Lara, para su impresión. A este tenor, Mosquera recuerda, en la Prefación, que iba a publicarse después del fallecimiento del maestro hispalense. Al margen de su testimonio, el manuscrito, escrito con caracteres caligráficos cuidados por obra del copista de La Psyche, está, en contraposición, plagado de errores, especialmente en los epigramas latinos ${ }^{51}$. Junto a dicha propuesta textual parcial, hay una impresión íntegra de la Sociedad de Bibliófilos Andaluces (Sevilla, 1876), que reproduce las lecturas imprecisas del testimonio colombino. Manuel Bernal, por su parte, ha acometido, por último, una edición con un sucinto estudio, valiéndose tanto de la fuente hispalense como del volumen de los Bibliófilos.

A la vista de esta tradición textual, se ha venido soslayando, en consecuencia, un segundo códice que debe ser considerado para el establecimiento de una rigurosa edición crítica de la Descripción y, por supuesto, en lo que hace a los epigramas contenidos en esta obra. Nos referimos al manuscrito R-49481 de la Biblioteca del Castillo de Perelada, cuyos folios 95 y siguientes son útiles para arrojar luz sobre esta tradición de fontes critica ${ }^{52}$. Con bastante certeza, estamos ante un estadio de redacción primigenio -como evidencia buena parte del manuscrito con una naturaleza in fieri-, sobre el que se hizo la copia del texto colombino, no corregido por Mal Lara. Esta fuente ofrece, al hilo de la obra, diversos comentarios e instrucciones para la organización de las piezas (así se indica en la tabla del manuscri-

51 Como ya señalara Rocío CARANDE en su estudio de las composiciones latinas: Mal-Lara y Lepanto: los epigramas latinos de la Galera Real de Don Juan de Austria, Caja San Fernando, Sevilla, 1990.

${ }^{52}$ En adelante, para el cotejo de testimonios, nos referiremos al manuscrito colombino como $C$. Sus lecciones suele seguirlas Bernal $(B)$ en su volumen referido, aunque con diversos lapsus calami en cuanto a la transcripción. Escaso valor posee, al tiempo, la edición de los Bibliófilos por sus abundantes errores. En lo que hace al códice de Perelada, lo denominaremos con la sigla $P$. Por último, las negritas en la collatio codicum permiten marcar las variantes. 
to) mientras que no ostenta, en cambio, los preliminares de presentación en los que participó Mosquera. Al tiempo, tiene visos de ser un códice que parte de una redacción autorizada por el humanista por la fidelidad de su contenido, si nos atenemos al diseño último dado por el documento colombino. Se comprueba, asimismo, cómo, a medida que avanza la obra, se acelera el proceso de escritura, seguramente por la premura del encargo. Resulta de interés constatar, de la misma forma, que en este manuscrito quedan integrados poemas de naturaleza varia y autores heterogéneos, entre otros, Mosquera.

En lo concerniente a su descripción bibliográfica, frente al códice 2051 de la Biblioteca de Catalunya -considerado autógrafo de Mosquera ${ }^{53}$-, éste constituye un manuscrito misceláneo y facticio en folio que comprende un total de 240 hojas, normalmente con reclamo. Carece de tapa y de los folios que van del 7 al 29, y presenta otros en blanco; el último, numerado bajo el 251, obedece a un error. $\mathrm{Su}$ encuadernación, efectuada en el siglo XIx, se antoja frágil y poco consistente. Su tabla brinda, a modo de índice, una relación de obras tanto en prosa -especialmente tratados- como en verso, en su parte final. Así, comienza el testimonio con la Genealogía de los mansos (f. 1) para seguir con una descripción de Galicia, cuerpos de santos, linajes, etc. (f. 8). En este conjunto híbrido pero vinculado a la temática nacional, se alza, a su vez, una relación de los reyes españoles desde época remota (De los reyes q[ue] reynaron en España después del diluvio..., f. 30), texto que da paso a los tratados legales Defensio statuti toletani... (f. 69) e Instrucciones para fundar cofradia en alibio de los pobres de la cárcel... (f. 76). Es en este lugar donde se encuentra la Descripción de la Galera Real de el s[erenísim]o D. Juan de Austria con varias instrucciones para los repartimentos de las piezas (f. 95). Con todo, no parece casual -por la añoranza de Mal Lara respecto a la política de Carlos V y su frustrada esperanza en el príncipe Carlos- que a continuación rece la Coronación del Emperador Carlos V (f. 130), perteneciente al segundo libro de la Descripción-aunque no se indique aquí-, así como unas Octavas a la muerte del príncipe don Carlos, hijo de Phelipe $2^{\circ}$ (f. 177) ${ }^{54}$. En el centro de ambos pilares despunta, por añadidura, el poema épico Descripción de la batalla naval, de Pedro de Acosta (f. 156) ${ }^{55}$. Finalizado este acopio de obras, accedemos a un corpus poético, según se indica en el epígrafe $Y$ otras obras en verso muy célebres a otros y diferentes asumptos por varios autores. Entre ellos se descubren disímiles compo-

53 Fue publicado por Guillermo Díaz-Plaja en su ed. de MosQuera, Obras, t. 1: Poesias inéditas.

54 Figura en la que confiaron, en vano, Mal Lara y el conde de Gelves con vistas a un futuro cambio de reinado.

${ }^{55}$ Curiosamente, en relación con el género literario más apreciado por Mal Lara en su deseo de medrar en la Corte. 
siciones de Mosquera ${ }^{56}$, Figueroa, Medina, Silvestre y otros autores de carácter anónimo. Estamos, en fin, ante un primer estadio, previo al definitivo, de la Colombina, manuscrito en el que Mosquera ha insertado ya sus versos preliminares con el propósito de presentar la Descripción.

De interés son, por otra parte, en el marco del testimonio, las apostillas comprendidas en el cuerpo de la obra sobre su proceso de redacción primigenia así como de la organización interna de las piezas. De esta suerte, en el f. 195r figura, después del título Exhortación al serenísimo señor don Juan de Austria, capitán general de la mar, la nota "es lo último que se ha de poner en la Galera Real". Este poema (ff. 195r-195v) no se halla en el conjunto de la Descripción sino a continuación del intitulado De Marcial. Vitamque faciunto beatiorem. Paraphrasis Ode (f. 194v), cuyo incipit es "Lo que haze la vida / en este suelo bienauenturada". En cualquier caso, se erige como la pieza con la que se cierra la Galera Real, según ratifica $C$.

Tras esta Exhortación, brilla una Oda hecha en loor del serenissimo don Iuan de Austria, donde el cielo le ofreçe fauor a tan sancta empresa (ff. 195v-196r). Corresponde, justamente, a unos versos no ubicados en este orden en la Descripción, aunque estén integrados en la mis$\mathrm{ma}^{57}$. La obra no contiene, en este lugar -si bien figura más adelante-, dicho paratexto pero sí este conciso poema junto a la sección De los planetas. En el lado superior de estos versos, aparece la indicación de lema (f. 195v). Se trata, por ende, de la primera referencia que acompaña la Declaración, a la que siguen, a modo de compendio -y no aparece así en la redacción definitiva de la obra a tenor de $C-$, los apuntes relativos a los términos (f. 196r) Mercurio, Venus, Sol, Marte, Iúpiter, Saturno, Aries, Taurus, Gemini, Cáncer, Leo, Virgo, Libra, Scorpius, Sagitarius, Capricornius, Aquarius y Piscis.

Con este postrero lema de la última declaración se cierra, en el diseño general de la Galera Real, el segundo libro. Sin embargo, en ningún caso se ofrece aquí el comentario extenso en prosa ni tampoco cada uno de los versos latinos que lo encabezan ${ }^{58}$. Es más, en este marco, continúan los esbozos correspondientes al libro tercero y luego debería constar, si atendemos al plan definitivo ${ }^{59}$, la Oda hecha en loor del sereníssimo don Iuan de Austria. Después de Piscis se locali-

${ }^{56}$ Recuérdese en este contexto, como se ha apuntado, su íntimo vínculo laboral con Mal Lara y, sobre todo, en lo que atañe a la Descripción.

57 Véase la ed. cit. de Bernal, pp. 432 ss.

58 Éste fue, de hecho, el plan definitivo de Mal Lara. Tal desmembración de las composiciones respecto al proyecto general último viene a insistir en la idea de que $P$ constituyó un testimonio crucial al asignar un orden a las distintas piezas.

${ }^{59}$ Cf. la ed. cit. de Bernal, pp. 485-492. 
zan, por añadidura, las siguientes voces: Arcti.$^{60}$, Bootes, Corona sep. ${ }^{61}$, Engonasis, Lyna ${ }^{62}$, Olor, Cepheus, Cassiopeia, Andrómeda, Perseus, Auri-

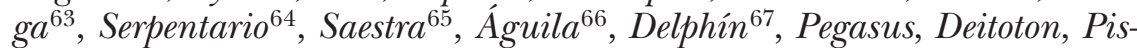
trix, Eridanus ${ }^{68}$, Lepus, Orión, Canis ${ }^{69}$, Canicula, Argo ${ }^{70}$, Centaurus, Ara, Hydra, Piscis notius, Corona Austra ${ }^{71}$ y Círculo lácteo.

Junto a la referida Oda hecha en loor del serenissimo don Iuan de Austria..., en $P$, tras la presencia de una línea en aras de marcar la separación, contamos con la Elegía primera a la muerte de Garcilasso de la Vega ("Cisnes de Bethis, que en su gran ribera") de Mosquera, con idéntica letra a la de los materiales poéticos de la Galera Real señalados. Por tanto, composiciones de esta empresa se conjugan con otras de nuestro autor, quien contribuyó en la misma. En el vuelto de este folio concluye, de hecho, la Elegía I, que ostenta correcciones ${ }^{72}$, para dar comienzo a la segunda pieza de tono élego de Mosquera: A la muerte de la señora Doña Juana Enríquez, muger del señor liçençiado Salgado Correa, juez de la Casa de la Contratación de Sevilla. Elegía segun$d a$ ("Si el alto y poderoso entendimiento"). Cuando finalizan estos versos (f. 198v), se descubre otro notorio poema de Mosquera para la Descripción, a saber: el Vaticinio de Proteo, dios del mar, de las deidades de los gentiles, al Sereníssimo don Joan de Austria. Christóual Mosquera de Figueroa. Con respecto a las lecciones de $C$-respetadas por $B-, P$ ofrece claras variantes, ya en el paratexto. Precisamente, al Vaticinio le vamos a dedicar cierto espacio, en cuanto a sus problemas textua-

60 Ed. cit. de Bernal, p. 455. Dicho texto tiene una errata: "templarán los más fieron corazones", frente a la lectura de los manuscritos: "templarán los más fieros corazones".

61 Corona septentrional en la ed. cit. de Bernal, p. 456. Los versos de Pcorresponden a Corona borealis en $B$-que sigue el testimonio de $C-$, con la variante: "biva el joven, alta dotado". Sin embargo, es un verso hipermétrico, si atendemos al cauce estrófico de la lira. $P$, en cambio, ofrece otra lección, correcta, al menos causa metri: "biva el joven, dotado".

62 Responde a un error de transcripción de $P$. Debería figurar lyra.

63 El lema que recogen $C$ y $B$ (p. 466) es Heniochus, soslayado en $P$. Con todo, el término auriga resulta la piedra angular del comentario de Mal Lara, no presente en esta sección de $P$.

${ }^{64}$ Se constituye en el arranque del comento, a tenor del diseño definitivo de $C$. Sin embargo, los versos rezan aquí tras la voz Ophiuchus. El copista de $P$, ante la opción de seleccionar ambos términos -como en esta ocasión, entre Ophiuchus y Auri$g a-$, se decanta por el más común para ofrecer un texto que no dificulte su lectura.

65 Error de $P$. La lección correcta sería saeta o sagitta, como constan en $C$ y $B$.

66 C, B: Aquila.

67 C, B: Delphinus.

68 El texto de Bernal ofrece una errata: "Eridano, qua a Itallia fértil riega”. La enmienda ope codicum propuesta es la siguiente: "Eridano, que a Italia fértil riega".

69 C, B: Canis maior.

70 Argo navis en $C, B$.

71 C, B: Corona Austral o Corona Australis.

72 Es el caso de Sebetho por Sabeto. 
les, tanto por su relevancia en el conjunto de la Descripción como por su vínculo con Mal Lara, al que Mosquera homenajea.

En $P$ aparece, en primer lugar, una nota debajo del título, muestra de la necesidad de ubicar las piezas para el planteamiento definitivo. Ésta es la siguiente: "Es lo segundo que se ha de poner en la Galera Real". Y en efecto, constituye el segundo preliminar, hecho por Mosquera, según muestra el diseño último de la Descripción, a tenor del cotejo de $P$ y $C$. El precedente resulta un prefacio de nuestro poeta a los lectores explicando cómo Mal Lara no pudo ordenar estas composiciones para su impresión. Tales detalles vienen a indicar, de hecho, que Mosquera manipuló los textos autorizados por el humanista, puesto que él mismo había colaborado en el plan primigenio. Por ello, preparó los paratextos a fin de presentar la obra al tiempo que perfiló la diátaxis estructural que hoy conocemos. Por tanto, gracias a $P$, tenemos noticia de una prístina fase de distribución de las piezas -dirigida por Mosquera ${ }^{73}$, mientras que $C$ ha tenido ya en cuenta tales instrucciones. Aducimos, en el Apéndice I, el cotejo de las variantes de redacción, en consonancia con la preceptiva collatio codicum, con el objeto de asentar las bases para una edición crítica del Vaticinio, poema que relaciona, desde la temática mitológica ${ }^{74}$ y desde el afecto, a Mosquera con Mal Lara. La lectio última para la constitutio textus sería, claro está, la facilitada por $C$. No obstante, el acopio de lecciones permite adentrarnos en el paulatino proceso de composición del texto.

Finalizado el Vaticinio, se inicia otra pieza de Mosquera ajena a la Descripción, a saber: A don Alonso Pérez de Guzmán, el Bueno, Duque de Medina Sydonia. Christóual Mosquera de Figueroa. Entre estos versos se integra un Soneto a Fernando de Herrera ("Cesse, que tiempo es ya, el lamento mío"), que acusa un error de atribución, dado que la autoría corresponde al Divino $^{75}$. Seguramente el poema fue copiado en dicho manuscrito, entre otras razones, por el hecho de dirigirse Herrera a Mosquera $^{76}$. Por tales inexactitudes en cuanto a la asignación de composiciones, cabe preguntarse, dada la labor conjunta de los miembros de la Academia en la Descripción ${ }^{77}$, si los lemas referidos, disociados

${ }^{73}$ De ahí que se encuentren las piezas referidas entre otras suyas no relacionadas con la Descripción.

${ }^{74}$ Se trata, en efecto, de un motivo recreado en La Psyche (XI, 782-906) de Mal Lara.

75 Como ya corrigiese Díaz-Plaja (op. cit., p. 196). Puede leerse el poema en la ed. de Herrera al cuidado de Cristóbal Cuevas (Cátedra, Madrid, 1985, p. 339).

${ }^{76}$ Éste, a su vez, habría de corresponderle con el soneto "Si no entendiese que un doliente pecho"; cf. la ed. cit. de Díaz-Plaja, p. 197.

77 Para este trabajo académico colectivo -en el que estaba integrado Mosqueravéase el texto editado, a modo de apéndice, por Francisco J. Escobar, "Noticias inéditas sobre Fernando de Herrera y la Academia sevillana en el Hércules animoso, de Juan de Mal Lara", Epos, 16 (2000), 133-155. 
del comentario de Mal Lara e insertos entre los poemas de Mosquera, son responsabilidad suya -al igual que el Vaticinio- y no del preclaro humanista.

Por otra parte, en el f. 130r -afectado por visibles manchas de humedad en la parte inferior ${ }^{78}$-, se abre otro apartado de la Galera Real (la Coronación del Emperador Carlos V, Nuestro Señor), aunque no se indique en la tabla introductoria del códice. Su naturaleza genérica corresponde, en síntesis, a la de un texto en prosa, a línea tirada, que en el diseño global de la obra, si atendemos al testimonio $C$ -el último estadio ${ }^{79}$-, se incluye en el libro segundo, después del epígrafe Del pavimento de la popa y antes de los Elogios de los seis capitanes ilustres antiguos a la mano derech $a^{80}$. Desde el punto de vista del contenido, no deja de ser una lectura más de la consabida aretalogía del Emperador, como plasma en verso y también de forma encomiástica Mal Lara en el Hércules.

En el folio en el que concluye la Coronación (131v) comienzan, por último, los Elogios de los seis capitanes ilustres antiguos a la mano derecha hasta culminar en el 132r. Son numerosas las variantes que conforman el aparato crítico ${ }^{81}$. Un buen número de ellas proporcionan datos sobre el complejo proceso compositivo seguido. En lo que hace a las lecciones, en casos puntuales, se detectan errores por parte del copista de $P$. Al tiempo, sobresalen las distintas variantes redaccionales que ostentan los dos estadios de la obra. Vemos una muestra de ello en el Apéndice II.

En otras ocasiones, empero, hay añadidos supra lineam, anotaciones aclaratorias o correcciones en $P$ que nos permiten reconstruir el proceso compositivo fijado hasta llegar, en fin, al texto de $C$ (seguido por $B$ ). A veces, incluso ambos códices coinciden en las lecciones. Sin embargo, aun existiendo estas concomitancias textuales, resultan de interés las apostillas insertas por el amanuense de $P$ al efectuar la copia (véase Apéndice III). Es más, otro grupo de variantes pone de relieve, al igual que se ha señalado para el Vaticinio de Mosquera, que $C$ ostenta el estadio último respecto al proyecto general de la obra. Lo comprobamos con sendos ejemplos en el Apéndice IV. Por último, idénticas directrices, en cuanto al aparato crítico, encontramos en la sección De las artes liberales, Astrología, Estaciones del año, De los signos del zodíaco, a tenor de sus variantes (cf. Apéndice V).

En consonancia con los datos expuestos, si $C$ se establece como el manuscrito base en la constitutio textus, con vistas a ofrecer el último estadio de la Descripción, en cambio, $P$ descubre el delicado proceso

78 Como también los sucesivos folios.

79 Así lo mantiene $B$ (ed. cit., pp. 363 ss.).

80 Comienza por Minos, rey de Creta (véase la ed. de Bernal, pp. 370 ss.).

81 Un análisis exhaustivo ofrecemos en el estudio referido, junto a otras múltiples cuestiones que no podemos atender aquí por razones de espacio. 
de ordenación y diseño dispositivo previo ${ }^{82}$, asumido por Mosquera al estructurar el contenido textual para su publicación. Tal proceder explica, por añadidura, que rece como adalid en la presentación de la obra con un destacado preliminar, el Vaticinio de Proteo, localizado, precisamente, junto a esta versión de la Galera Real en $P$. Ello no es de extrañar, dado los estrechos lazos de colaboración establecidos por Mosquera con Mal Lara en el ámbito de su Academia ca. 1565, como se ha señalado. Lo demuestra que éste tuviese en su poder el Eliocriso en 1568, según refiere en la Galera Real, o lo mencione entre sus amigos, de forma laudatoria, en el Hércules. A este hecho cabe sumar los errores deslizados por el copista de $C$-el mismo de La Psyche- en un texto cuya factura definitiva no pudo ser revisada por Mal Lara ni por Mosquera, sobre todo, en lo que hace a los epigramas. En definitiva, para la propuesta rigurosa de una edición crítica de la Galera Real, resulta primordial tener en cuenta las distintas lecciones del códice de Perelada.

Francisco Javier Escobar Borrego

Universidad de Sevilla

82 Incluso de intervención en el texto, si atendemos a la costumbre practicada en el entorno sevillano en cuanto a la participación colectiva en obras de envergadura y aliento. Sucede con el Hércules de Mal Lara -con poemas de Herrera, Sáez Zumeta o Cristóbal de las Casas-, las Anotaciones del Divino, gracias a la ayuda de Medina, Girón y el canónigo Pacheco, o el Libro de descripción de verdaderos retratos, en el que el pintor Pacheco, sobrino homónimo del anterior, inserta diversos poemas de su tío, Rioja y otros vates destacados del Parnaso hispalense. 


\section{APÉNDICES}

\section{Apéndice I. Vaticinio de Proteo}

$C, B$ : Vaticinio de Proteo al Sermo. Sr. Don Juan de Austria antes que sucediesse la batalla naval. El licenciado Mosquera de Figueroa. $P$ : Vaticinio de Proteo, dios del mar, de las deidades de los gentiles, al Sereníssimo Don Joan de Austria. Christóual Mosquera de Figueroa.

$C, B$ : a la par se reparan: desseosos. $P$ : a un punto se reparan, desseosos.

$C, B$ : de oír al nuevo y milagroso canto. $P$ : de oýr el nuevo y milagroso canto.

$C, B$ : la ilustre imagen sueltos los cabellos. $P$ : la bella imagen sueltos los cabellos.

$C, B$ : Dexad, Nereides, el sagrado assiento. $P$ : Dexad, Nereydes, el dotado assiento.

$C, B$ : veréis a Carlo, que en el cielo mora / y su sombra visita mar y tierra. $P$ : veréis de Carlo, que en el cielo mora / que su sombra visita mar y tierra.

$C, B$ : perded todo temor, y estad atentas. $P$ : perded todo temor, y estad atentas. [En $P$, después de perded aparece una tachadura sobre una $a$ ].

$C, B$ : que muertes y heridas / serán de los contrarios recebidas. $P$ : que golpes y heridas / serán a costa de contrarias vidas.

$C, B$ : que en Asia mueve el sceptro poderoso. $P$ : que en Asia mueve el çetro poderoso. [Variantes gráficas].

$C, B$ : Resplandece en el mar el bello Marte / con alto yelmo, y con gallardas plumas / cercado de altos héroes valerosos. $P$ : En el mar resplandeçe el bello Marte / alta çelada con gallardas plumas / cercado de sus héroes valerosos. [Transmutación del orden en las variantes redaccionales].

$C, B$ : que arrojan los cavallos generosos. $P$ : que arrojan los cavallos generosos. [La variante que aparece finalmente en el manuscrito colombino, generosos, la añade Mosquera al marcar el vocablo poderosos. En $P$ corrige el autor, según refleja la letra autógrafa ${ }^{83}$, su versión originaria. Ello demuestra que $P$ ofrece un estadio anterior a $C$ en lo que a la obra se refiere].

$C, B$ : que en campo provocados y encendidos. $P$ : que en campo alborotados y encendidos.

$C, B$ : deste arte le esperavan / y al bárbaro enemigo s'acercavan. $P$ : assí se prouocauan / y al bárbaro enemigo se acercauan.

$C, B$ : El viento poco a poco va esforçando / y el sol subido en medio de su cumbre. $P$ : El viento poco a poco fue esforçando / y el sol en medio de su immensa cumbre.

$C, B$ : de Phaetón temerario y atrevido. P: de Faetón temerario y atreuido. [Variantes gráficas].

$C, B$ : ahora son contrarios señalados. $P$ : ya son sus enemigos declarados.

$C, B$ : rompen a los contrarios las entrañas. $P$ : rompen a los contrarios las entra[ñas]. [En $P$ se interrumpe el final de este verso así como en la misma estrofa dos veces más].

\footnotetext{
${ }^{83}$ La que publica Díaz-Plaja en su ed.
} 
$C, B$ : con la antigua Corintho y sus montañas. $P$ : con la antigua Corintho y sus mon[tañas]. [El copista de $P$ cercena el cierre versal; en esta estrofa sucede también en sendas ocasiones].

$C, B$ : tiembla Neptuno en su profundo assiento. $P$ : tiembla Neptuno en su profundo assien[to]. [Como en los casos precedentes, en $P$ no aparece la parte última de este verso].

$C, B$ : s'estremeció a la par con Helicona. $P$ : en sí se estremeció con Elicona.

$C, B$ : y encendiendo en sus aras nuevas lumbres. $P$ : y encendiendo en sus aras nueuas lum[bres]. [En $P$ se trunca el final del verso].

$C, B$ : el oráculo Délphico sangriento. $P$ : el oráculo délfico sangriento. [Variantes gráficas].

$C, B$ : pronostica al de Austria la corona. P: prognostica al de Austria la corona. [Variantes gráficas].

$C, B$ : se pierde libertad y gloria junto. $P$ : la libertad se gana y pierde junto.

$C, B$ : con los ricos despojos de Oriente. $P$ : con los ricos despojos del Oriente.

$C, B$ : y a la par con tu edad, tu suerte crece. $P$ : y junto con tu hedad, tu suerte crece.

$C, B$ : todo será rendido. $P$ : todo verás rendido.

$C, B$ : publíquense tropheos y victoria. $P$ : publíquense trofeos y vitoria. [Variantes gráficas. En cualquier caso, se tiende en $P$ a simplificar los grupos consonánticos, sobre todo, de raíz latina, pero no siempre; véase infra].

$C, B$ : lugar junto al Arturo, estrella fría. $P$ : lugar junto al Arcturo, estrella fría. [Variantes gráficas].

$C, B$ : en Náyades han sido convertidas. $P$ : fueron en sacras Ninfas convertidas $^{84}$.

$C, B$ : Proteo lleno de spíritu divino. P: Proteo lleno de espíritu divino. [Variantes gráficas. En la estrofa en cuestión el folio presenta una fisura que, en este caso, no impide leer los versos].

$C, B$ : el viento se levanta furioso. $P$ : el viento se levanta poderoso.

$C, B$ : y las horribles phocas rebramando. $P$ : y las horribles focas rebramando. [Variantes gráficas].

$C, B$ : mostrando en toda parte. $P$ : cantando en toda parte.

\section{ApÉndice II}

$C, B$ : solamente él tenía valor. $P$ : él sólo tenía valor. [Variantes en el $Q u a r$ to capitán, don Alfonso, rey de Aragón y Sicilia].

$C, B$ : cargo. $P$ : cargas.

$C, B$ : huían. $P$ : huyó.

$C, B$ : los engaños. $P$ : lo engaños. [Error de $P$. Con todo, cabe la posibilidad de que en el autógrafo de Mal Lara figurase esta lección, porque, como sucede en el Hércules -escrito con su caligrafía-, la aspiración en posición implosiva le llevaba, en ocasiones, a proceder de esta manera].

84 Seguidamente, tanto en $C$ como en $P$ encontramos los mismos versos: "vos diosas de belleza / en immortalidad constituidas / seréis, si disfraçadas / quedáis, y en estas naves transformadas". Sin embargo, cabe referir que en este último manuscrito existe una fisura en el folio. 
$C, B$ : yendo don Hugo de Moncada. P: yendo con Hugo de Monçada.

[Variantes. En $P$ está tachada Gen, seguramente por un salto de lectura con el vocablo Génoua, que aparece después].

$C, B$ : hazía el turco grande aparato. $P$ : el turco hazía grande aparato.

[Como en otros casos derivados de la collatio codicum, constan aquí sendas variantes debido a una transmutación del orden].

\section{ApÉNDICE III}

$C, B$ : dize averse enamorado. $P$ : dizen auerse enamorado. [En $P$ dizen aparece supra lineam en tanto que se descubre tachado el vocablo dezían. Se trata, en efecto, de caracteres caligráficos parejos].

$C, B$ : las gentes a salir a mirarlo. $P$ : las gentes a salir a mirarlo. [Idéntico texto. No obstante, en $P$, a salir se indica supra lineam].

$C, B$ : tan grande. $P$ : tan grande. [Estamos ante la misma lección. Con todo, en $P$ se halla, previamente a grande, una tachadura por error del amanuense].

$C, B$ : quisiese. $P$ : quisiese. [Como en el caso anterior, en $P$ encontramos, antes de quisiese, un término tachado por un lapsus en la copia].

$C, B$ : halló todo el pueblo. $P$ : halló todo el pueblo. [P: todo supra lineam].

$C, B$ : la nueva de la muerte. $P$ : la nueva de la muerte. [ $P$ : nueva de la supra lineam].

$C, B$ : sobre Augusta. $P$ : sobre Augusta. [P: tachada A antes de Augusta].

$C, B$ : Palermo, siendo capitán el abbad Palmero. P: Palermo, el abbad Palmero. [El escribano de $P$ omite siendo capitán el abbad Palmero puesto que aparece tachado y alli, que es la iunctura hallada a continuación de esta frase, a tenor del diseño último de la obra].

$C, B$ : y Avelino. $P$ : y Avelino. [P: tachada $a$ antes de Avelino].

$C, B$ : cobró Roger. $P$ : cobró Roger. [ $P$ : suprimida acertadamente, mediante línea, una a en cobró a Roger. Si se hubiese conservado la vocal, estaríamos ante un sentido erróneo. Por tanto, para la fijación del texto, delenda est].

$C, B, P$ : [En $P$, en lo que hace al Elogio de Roger de Loria, después del primer verso, se percibe un intento de redacción por parte del copista para el segundo, distinto del que conservamos hoy gracias a $C$. Sin embargo, está tachado laurea Rogerio. Se trata, en cualquier caso, de un error. De tal manera, el amanuense omite, involuntariamente, un verso al tiempo que procura transcribir el tercero que comienza así].

$C, B$ : de Ruisellón. $P$ : de Ruysellón. [ $P$ : de añadido supra lineam].

$C, B$ : iactatum cassibus. $P$ : iactatum casibus. [En cuanto al epigrama latino Elogio del rey Alfonso, ambos códices brindan la lectura aducida pero en $P$ se localiza entre iactatum y cassibus un signo marcado con una raya].

$C, B$ : permisit. P: permisit. [En el epigrama Elogio del rey Alfonso, contamos con idénticas lecciones aunque se descubre, antepuesto a permisit, el inicio de este vocablo tachado. El copista, en efecto, no familiarizado con el latín -al igual que el de $C$-, redactó, por un lapsus calami, pre].

$C, B$ : de Sicilia. $P$ : de Sicilia. [P: de está añadido supra lineam].

$C$, B: empresa. $P$ : empresa. [ $P$ : la $a$ ha sido objeto de corrección].

$C, B$ : peleó con. $P$ : peleó con. $[P$ : antes de con se descubre marcada una $a]$.

$C, B$ : columnas. $P$ : colunas. [P: supra lineam cobanas]. 
$C, B$ : auertere. P: auertere. [Idéntica lección en lo que hace al Elogio de Andrea Doria. Dialogismus. Viator-Neptunus. Sin embargo, como en otros casos, $P$ presenta una tachadura antes de auertere].

$C, B$ : El sexto capitán, el César Carlo Quinto Máximo . $P$ : [ $P$ omite el título. En cuanto al plano de la héuresis, sobresale la relación temática de esta pieza con el Hércules animoso].

$C, B$ : todas juntas. $P$ : todas juntas. [P: todas supra lineam].

\section{ApÉNDICE IV}

$C, B$ : vellocino de oro. $P$ : velloçino de oro. [En $P$ aparece tachado dorado para sustituirlo por la lectura incorporada en $C:$ de oro].

$C, B: \tan$ grande aprieto. $P: \tan$ grande aprieto. [En $P$ consta tanto aprieto -marcando el copista -to aprieto- en aras de reemplazarlo por la lección de $C$, tan grande aprieto, que resulta ser la definitiva].

\section{ApÉndice V}

$C, B$ : Descripción de la Galera Real. De las artes liberales. $P$ : De las artes liberales. [Dos variantes con supresión parcial en $P$ ].

$C, B$ : todas juntas. $P$ : todas juntas. [P: todas supra lineam].

$C, B$ : para significar. $P$ : para significar. [P: tachadura antes de para significar].

$C, B$ : En el primero. $P$ : En el primero. [ $P$ : corregido es por en mediante una línea y añadido supra lineam].

$C, B$ : ensangrentado. $P$ : ensangrentado. $[P$ : insertas supra lineam las dos primeras $n]$.

$C, B$ : entre ellos. $P$ : entretallado. [Variantes. Éste, junto a otros epigramas, había sido recogido en $P$ primeramente aunque sin la explicación en prosa. Ahora reaparecen, pero ya acompañados de dicho comento].

$C, B$ : vulgo. $P$ : vulgo. [En $P$ se corrige mundo por vulgo, supra lineam. Esta última constituye la lectura definitiva que permanece en $C]$. 
